\title{
University Students' Multidimensional State Boredom and Strategies to Cope with Classroom Boredom
}

\begin{abstract}
Mehdi Solhi
Istanbul Medipol University

Correspondence concerning this article should be addressed to Mehdi Solhi, Istanbul Medipol University, 34810 Beykoz/ Istanbul, Turkey. E-mail: solhi.mehdi@gmail.com

This study sought to examine how university students' state boredom dimensions (i.e., disengagement, high arousal, low arousal, inattention, and time perception) and their boredom coping strategies (i.e., cognitive approach, behavioral approach, cognitive avoidance, and behavioral avoidance) in the classroom are mediated in relation to gender and academic year. A total of 186 undergraduate students from a Turkish university, majoring in English language teaching in the faculty of education voluntarily participated in the study. The results indicated that the male participants experienced higher levels of boredom than the females in all levels of the state boredom. Additionally, the females had more inclination to use cognitive approach, while the male participants exhibited more behavioral approach to cope with boredom. Secondly, the participants with different academic levels only scored differently in disengagement, a state boredom dimension, and in cognitive approach, a boredom coping strategy. The findings highlight the significance of identifying student boredom and thereby specifying strategies to relieve their boredom in the classroom. Indeed, by gaining a proper understanding of the reactions triggered by boredom in classes, we would be able to spot the developmental paths of these reactions and thereby adopt the necessary measures to deal with student boredom.
\end{abstract}

Keywords: state boredom dimensions, boredom coping strategies, university students

\section{Introduction}

Affective factors commonly refer to the emotional domain of human behavior, and, as a hotly debated topic in second language acquisition (SLA) since the 1970s, has presented important implications and practical applications to language teaching methodology (Brown, 2014). Negative emotional reactions that result from negative feelings or experiences in language learning can act as a barrier to acquisition (Yule, 2014). Intricately intertwined with different affective factors such as inhibition, self-esteem, motivation, anxiety, and risk taking, the construct of boredom also fulfills a primary role in SLA. Over the past several years, the pendulum has swung in favor of an interest in learners, rather than only being concerned with teachers, textbooks, and methods (Yule, 2014) in language education. Hence, this shift is regarded as one of the most fundamental transitions in the field of language learning and teaching, and thereby the focus on the learner is now considered to be of paramount importance in SLA.

\section{The Construct of Boredom in Education}

Boredom is described as a deactivating emotion (Pekrun, 2006), an undesirable and displeasing feeling (Mikulas \& Vodanovich, 1993), and an apparently never-ending unpleasantness (Fahlman et al., 2013). It has also been argued that boredom is a more frequently experienced emotion than anxiety (Pekrun et al., 2002), and one of the most common complaints in educational settings (Busari, 2018). Indeed, it possesses various constituents (Pekrun et al., 2010), and is likely to arise from a complex, achievement-related emotion (Sharp et al., 2016). Specifically, academic boredom is a type of emotional response that has been reported to be associated with lower academic attainment (Pekrun et al., 2010), academic decline (Mann \& Robinson, 2009; Pekrun et al., 2014), and educational malfunctioning (Daniels et al., 2015). The typical symptoms of academic boredom may include yawning, being drowsy, continuously watching the clock, resting head on hand, and slouching in the classroom. 
More than two decades ago, Fisher (1993) asserted that the experience of boredom emerges not only from internal factors (e.g., individual differences, personality characteristics, various aspects of capacity, and mental health), but also from external causes (e.g., task and environmental conditions). In the same decade, Neu (1998) also conceptualized internal and external boredom as endogenous boredom and reactive boredom respectively. Not possessing strong incentives, activities (as external factors) that are void of stimulation are less likely to lead to educational attainment. Nor does success come without taking into consideration the individual characteristics (as internal factors) of the students. In fact, academic emotions involving boredom are identified as the feelings the students are likely to exhibit in the class while studying and taking tests and exams in educational environments (Pekrun et al., 2011), and are characterized with subjective control and value perceived by learners in the control-value theory (Pekrun, 2006). This theory of emotion suggests boredom arises when students perceive that they do not have control over the things that are either far beyond or below their abilities (Goetz et al., 2006) and when they do not notice any benefit to their educational endeavors (Pekrun et al., 2011).

\section{Boredom Coping Strategies}

Students may employ a set of miscellaneous strategies to cope with boredom in educational environments. Taking a nap, doodling, daydreaming, reading or sending text messages, playing games, and disappearing during the mid-session break are some of Ward's ${ }^{1}$ first-hand observations of students' boredom coping strategies in educational settings. In Mann and Robinson's (2009) study, playing games on a cellphone, texting, leaving mid-session, doodling, coloring in letters on handouts, and deciding not to attend the next lecture were also reported to be some of the boredom coping strategies that university students tend to adopt.

Nett et al. (2010) examined the strategies that students adopt to deal with boredom at school and their relative effectiveness, and consequently identified four boredom coping strategies (i.e., cognitive approach, behavioral approach, cognitive avoidance, and behavioral avoidance). Both cognitive or behavioral approach strategies incorporate endeavoring to solve the problem itself, while avoidance strategies include sidestepping or escaping the difficulty. Cognitive approach strategies aim at altering the perception of the situation. To give an example, a language student might remind himself that a reading lesson is extremely important, despite knowing that is boring. This reminding strategy is likely to alter the student's perception without altering the situation and he may not consequently feel bored. Behavioral approach strategies, in contrast, include attempting to fundamentally change the exhausting situation. A student who finds the reading lesson boring might ask the teacher for more appealing tasks. If her request is fulfilled, the situation could be favorably changed, and her boredom could be relieved. Even if her demand is likely to be denied, her attempt to make the teacher cognizant of the fact that the students are bored might lead to the teacher adapting the lesson.

On the other hand, avoidance strategies aim at helping students disregard the exhausting situation, either by thinking of something completely different (i.e., cognitive avoidance) or occupying themselves with something not related with the situation (i.e., behavioral avoidance). For instance, a student might occupy her thoughts about her plan after the lessons so as to evade the boring situation without disappearing from her lessons, or she may chat with a classmate during the lesson to manage the boring situation in the class. Chatting with a classmate during the lesson, texting, and playing games on a cellphone are other typical behavioral avoidance strategies in the classroom.

\section{Boredom in Higher Education}

Undoubtedly, universities do not always supply the individual, social, and cognitive incentives required to actively engage each student, despite their securing a seat to study at a preferred place. That is why not only K-12 students but also university undergraduates may feel bored in school (Sharp et al., 2020). Emerging from a variety of factors, as mentioned earlier, academic boredom is likely to be one of the causes of poor academic performance in university. Different dimensions of boredom in educational settings have been explored in various fields of inquiry, ranging from predictors of boredom at school (Daschmann et al., 2011) and students' achievement emotions in elementary school (Lichtenfeld et al., 2012), to boredom at higher education lectures (Mann \& Robinson, 2009), college students' boredom in under- and over-challenging situations (Acee, et al.,

\footnotetext{
1 Ward, T. (2003, May 20). I watched in dumb horror. The Guardian.
} 


\section{MEHDI SOLHI}

2010), and university students' patterns of boredom (Tze et al., 2014), resulting in various scales on experience of boredom such as the Precursors to Boredom Scales, the Achievement Emotions Questionnaire-Elementary School, the Boredom Proneness Scale, the Academic Boredom Scale, and the Academic Emotions Questionnaire respectively.

The Boredom Proneness Scale (BPS), developed by Farmer and Sundberg (1986), is the main inclusive measure of boredom that has been used extensively in empirical research for more than three decades (Fahlman et al., 2013). The initial BPS comprised 28 true-false items with an internal consistency of .79 (Farmer \& Sundberg, 1986). The original true-false items were then converted into a 7-point Likert-type format by Vodanovich and Kass (1990) so as to heighten its sensitivity. This scale only assesses the trait boredom of the individuals, that is, the general tendency to experience boredom in different situations, and does not determine the state boredom, which is the definite experience of boredom in the moment. Indeed, state boredom, contrary to trait boredom, is the experience of fatigue in the moment and is identified with various psychosocial issues (Hunter et al., 2015). Asserting that there is a paucity of measurement tools for assessing the state boredom of the individuals, in a recent study, Fahlman et al. (2013) developed the Multidimensional State Boredom Scale (MSBS), based on a theoretically and empirically validated concept of boredom, which was shown to be invariant across gender and regarded as the first and only full-scale measure of state boredom. In Fahlman et al.'s study (2013), MSBS scores were reported to be significantly correlated with measures of trait boredom, anger, anxiety, inattention, depression, purpose in life, life satisfaction, neuroticism, and impulsivity.

Contrary to investigations on boredom, research on students' boredom coping strategies does not abound, and students' strategies to cope with boredom have only currently been scrutinized within a thorough theoretical framework (Eren, 2013). On the other hand, even though recent examinations have diagnosed different causes of boredom in educational environments, little is known about how the recognized causes of boredom link with coping with boredom (Daniels et al., 2015). Additionally, whereas student boredom at school has been extensively investigated and indicated to be linked to varying negative consequences such as poor academic performance, school discontent, and truancy in the aftermath of the experiences of boredom, little attention has been paid to the issue of boredom within higher education (Mann \& Robinson, 2009).

Although research has indicated a host of variables that mediate with boredom, investigations on how individuals' gender and academic level can play a mediating role between their state boredom dimensions and copying with boredom strategies have not been scrutinized closely. However, a wealth of studies (e.g., Deng et al., 2016; Fischer et al., 2018; Shields, 2013; Sundberg et al., 1991) highlight the undeniable role of gender in emotional psychology. Indeed, investigating both male and female individuals' differing responses to emotional triggers, here boredom, can pave the way for a better understanding of the extent to which they experience boredom and consequently how they cope with the feelings of boredom in educational contexts. Research on gender differences in educational psychology can obviously result in better measures of feelings of boredom.

Likewise, academic level in alliance with educational emotion has been the subject of investigation over the last decade (e.g., Beiter et al., 2015; Puthran et al., 2016; Respondek et al., 2017; Wang et al., 2012; Wyatt \& Bloemker, 2013). Exploring students' academic year as the second mediating variable in the present study can also be illuminating as the university students in these studies reported exhibiting different emotional responses in different academic years. Identifying the construct of boredom, as one of the most frequently experienced emotions in educational contexts, and the way it oscillates among the university students with different academic levels would be enlightening for teacher educators, curriculum developers, and educationists. The present study thereby sought to fill this research gap by investigating how university students cope with boredom in the classroom by identifying their state boredom dimensions using Fahlman et al.'s (2013) MSBS, and recognizing their strategies for reducing boredom by adopting Nett et al.'s (2010) Coping with Boredom Scale.

\section{Previous Research}

Whereas students' academic emotions and motivation have been subjected to close scrutiny in educational research (e.g., Altintas et al., 2020; Le \& Impett, 2013; Lerner \& Grolnick, 2020; Nezlek \& Kuppens, 2008; Ruan et al., 2020; Wood et al., 2003; Yeung \& Fung, 2012), the study of emotion in education has only recently been taken into account (Schutz \& DeCuir, 2002) and only in the recent past has academic boredom been a subject of 
inquiry in the literature (e.g., Acee et al., 2010; Goetz et al., 2014; Tze, 2011). The experiences of boredom in educational milieus have been investigated in respect of their associations with unsatisfactory accomplishment at school (Jarvis \& Seifert, 2002), high school dropouts (Wegner et al., 2008), achievements in school subjects (Eren \& Coskun, 2016; Mann \& Robinson, 2009; Pekrun et al., 2011; Raccanello et al., 2018; Sharp et al., 2020), reading comprehension performance (Shehzad et al., 2020), boredom coping strategies (Nett et al., 2010; Nett et al., 2011; Zhou \& Kam, 2017), cooperative learning (Fernández-Río et al., 2014), challenging situations (Acee et al., 2010), and perceived autonomy support (Tze et al., 2014).

Some strands of research have compared the boredom of university students from a cross-cultural perspective. Tze's (2011) study, for instance, with Chinese and Canadian students indicated a significant difference in the levels of boredom at university, advocating the claim that Chinese students have a higher boredom threshold than Canadian students in educational settings. The researcher also identified a significant difference between the Canadian and Chinese participants in terms of using boredom coping strategies in which Chinese students outperformed their Canadian counterparts in using varying boredom coping strategies to regulate their experience of boredom. In Tze's (2011) study, approximately 40\% of university students reported experiencing boredom in classroom at some point. In Mann and Robinson's (2009) study with university students' boredom coping strategies, almost a third ( $27 \%$ ) of the participants found most of the lectures boring at higher education. Indeed, the results indicated that around $60 \%$ of students find at least half of their lectures boring. Similarly, in an attempt to identify the factors that can potentially lead to boredom, Mann and Robinson's (2009) study indicated that laboratory work, online lecture notes, and PowerPoint without handouts are some factors resulting in students' boredom at higher education, while the least boredom causing teaching methods were reported to be group work outside lectures, PowerPoint with handouts, seminars, practical sessions, and group discussions in lectures. Indeed, this study underlines the significance of learner involvement and collaborative learning for alleviating the boredom experience, and thereby boosting acquisition in the classroom.

Tze et al. (2014) examined the patterns of change in classroom-connected academic boredom. According to the findings, the participants reported an overall increase in their boredom experiences. Specifically, this overall increase in classroom boredom did not significantly vary among students. The researchers attributed the increase to the method of learning such as didactic lecturing in tertiary education. However, despite the studies that reported the increasing pattern of change in classroom boredom (Ahmed et al., 2013; Tze et al., 2014), other scholars (e.g., Nett et al., 2010) asserted that individual students are at least somewhat responsible when they experience boredom. They take the view that despite the teacher's diligent attempts to prepare stimulating, hence not boring, tasks and learning environments, some students still may find the activities or the learning situation quite boring.

Along with the investigations into educational boredom, a series of studies also explored students' boredom coping strategies in the educational context. Nett et al. (2011), for example, examined students' boredom coping strategies at trait and state levels, administering a self-report questionnaire to 537 students at grade 11, more than half of whom (approximately 55\%) were female. The cognitive approach orientation led to a smaller degree of boredom. Indeed, the scholars argued in favor of interventions encouraging the employment of cognitive approach strategies to cope with boredom. They asserted that students need to be encouraged to bear responsibility for boredom experiences by devoting more attention to the perceived usefulness of cognitive approach strategies to reduce feelings of boredom, improve their motivation and attainment, and consequently promote a more pleasant learning experience for both learners and instructors alike in the classroom. In a different study on boredom coping strategies in the educational context, Eren (2013) explored the mediating functions of university students' boredom managing strategies in the relationship between their perceptions of instrumentality and different aspects of engagement. Perceived instrumentality, boredom coping strategies except cognitive-avoidance orientation, and four aspects of engagement (i.e., agentic engagement, behavioral, engagement, emotional engagement, and cognitive engagement) were reported to be significantly interrelated.

In a recent study examining the mediating function of coping strategies on students' procrastination and motivation, Zhou and Kam (2017) investigated the relationships among attainment purposes, procrastination, self-efficacy, and boredom coping strategies with a group of Chinese college students $(\mathrm{N}=506)$. The results indicated that both approach goals and self-efficacy predict approach-oriented coping strategies. In addition, avoidance goals were predictors of avoidance oriented coping strategies. Behavioral avoidance was also reported to significantly predict procrastination. Eren and Coskun (2016) also explored the intermediary 


\section{MEHDI SOLHI}

functions of boredom managing strategies and epistemic curiosity in the relationship between students' levels of boredom and achievement scores with more than 500 high school students. The findings indicated that all of the variables were significantly linked to each other. Specifically, interest-type and deprivation-type epistemic curiosity were reported to have significant mediating roles in the relationship between the level of boredom and achievement scores, and were shown to differ across gender, underlining that the achievement scores of female students were significantly higher than those of male students.

Fernández-Río et al. (2014) explored the effect of a cooperative learning-based intervention program on 264 in-service primary education teachers' feelings of boredom. The 12-week treatment for the experimental group was based on the intervention program, while that of the control group was a traditional instructional approach. The results showed a significant decline in boredom in the experimental group. In addition, in respect of gender, female primary education teachers reported significantly lower levels of boredom when learning was cooperative. The findings signified the importance of cooperative learning as a beneficial teaching model in teacher education. In a similar study on language students' boredom experience at university, Pawlak et al. (2020) explored 111 EFL university students' causes of boredom in practical English classes. The results revealed that the sophomores experienced higher levels of boredom during practical English classes than the juniors. The overall results indicated moderate levels of boredom for both groups. More precisely, both groups particularly experienced boredom by virtue of, say, repetitive or monotonous situations, the lack of a challenge in practical English classes, the lack of exciting and/or interesting things to do in the lessons, and the lack of diversity.

In a recent study, Shehzad et al. (2020) investigated the mediating role of boredom coping strategies in the relationship between reading boredom and reading comprehension performance. The boredom attributed to English language reading skills was reported to be significantly, although negatively, related to reading comprehension performance. Additionally, reading boredom indicated a significant and positive relationship with boredom coping strategies. Boredom coping strategies were also shown to play a mediating role between reading boredom and reading comprehension performance. Indeed, the results highlight the significant role of boredom coping strategies in the acquisition of reading skills.

In a qualitative study, Finkielsztein (2019) explored university students' behaviors when they felt bored in class, using the taxonomy of boredom coping strategies. The students reported using more cognitive approaches to cope with a boring situation at the beginning of their studies at university with a progressive decrease over time in their tendency to employ those same cognitive approach when coping with boredom. Finkielsztein (2019) associated this tendency for students' decreasing engagement with their studies with becoming accustomed to the role of a student in educational settings. As a result of being familiar with the procedures and the instructors, they discovered and learned how to deal with a boring situation. In his study, the students reported that they began looking for alternative cognitive involvement (cognitive avoidance strategy) when they found the situation boring. Some metaphoric expressions used by the participating students who referred to cognitive avoidance strategies were a state of numbness, freezing, hibernation, and sleep mode. In addition, behavioral avoidance strategies such as talking to classmates and surfing on the internet were reported to be used by university students in the majority of the boredom-induced situations in the classroom.

Students' perceptions of academic boredom have also been investigated in several studies. Hypothesizing that boredom is a situation-dependent and multidimensional construct, Acee et al. (2010) assessed students' beliefs on academic boredom in under- and over-challenging situations. Task-focused boredom was identified by the tedium and ineffectiveness of a task, while self-focused boredom was identified by dissatisfaction and frustration feelings. Investigating the relationship between boredom and achievement in a native language and mathematics domains with second and fourth-grade elementary school students, Raccanello et al. (2018) found that the second graders experienced lower levels of boredom than the fourth graders. In general, mathematics resulted in better emotions than the native language subject, as younger students mainly exhibited "higher levels of enjoyment and lower levels of boredom and anxiety compared with older elementary students” (p. 16).

Considering all the studies on K-12 and university students' educational boredom profiles, future teachers' boredom experiences in the classroom and how they cope with them using a variety of strategies would be illuminating to the teacher educators in teacher education programs as this emotion, as aforementioned, can 
undoubtedly play a debilitating role in learning. Additionally, the foreign language classroom is an actual learning environment, and the students' feelings and their actual experiences of boredom (i.e., state boredom) in this educational setting are likely to differ from the general boredom status (i.e., trait boredom) that they may possess. Indeed, educationists need to specify strategies to mitigate students' boredom in academic milieus (Tze et al., 2015) to pave the way for a more pleasant leaning environment. Identifying how they cope with boredom in the classroom would enable teacher educators to gain a proper understanding of reactions triggered by boredom in classes, and thereby spot the developmental paths of these reactions by adopting the necessary measures to deal with boredom experiences (Tze et al., 2015).

Thus, the present study sought to investigate university students' state boredom dimensions and their boredom coping strategies to investigate how they are mediated between gender and academic level. To this end, the following research questions and hypotheses were formulated:

RQ1: What is the gender-mediated relationship between university students' multidimensional state boredom and their coping with boredom strategies?

RQ2: Is there an academic level-mediated relationship between university students' multidimensional state boredom and coping with boredom strategies?

For the first research question, it was firstly hypothesized that female students would both report lower levels of boredom than the males in higher education, and thereby would be more likely to excel in coping with boredom in the classroom. In the second research question, it was hypothesized that the more advanced the students are in their academic studies at university, the better they would be able to cope with their state boredom.

\section{Materials and Methods}

\section{Research Design}

This is a primary cross-sectional research study in which two instruments were employed so as to collect data from a cohort of university students within a short period of time. The questionnaires asked participants to think of the dimensions of their state boredom and how they manage to cope with boredom experiences in the classroom.

\section{Participants}

Participants in the study were 186 undergraduate students from a Turkish university, majoring in English language teaching in the faculty of education. Students in their freshman, sophomore, junior, and senior classes were invited to voluntarily participate in the study. Of the sample of student participants, $27.4 \%$ ( $\mathrm{n}=51$ ) were male and $72.6 \%(n=135)$ were female. The freshmen constituted 30.1 percent $(n=56)$, sophomores 32.3 percent $(n=60)$, juniors 28 percent $(n=52)$, and seniors 9.7 percent $(n=18)$ of the whole sample of participants. Although convenience sampling was used in the study, each member of the population received an invitation to voluntarily take part in the study and had an equal chance of participation.

\section{Data collection}

All the responses were collected from the participants using an online survey development platform (i.e., surverymonkey.com). The online generated link for the survey was sent via email to the cohorts of freshmen, sophomore, junior, and senior students in the department, and a deadline was set to fill in the questionnaires. In the classroom, the required information was also provided to the students regarding the study. They were informed that the investigator was always available to respond to questions or offer explanation if needed. A satisfactory response rate was obtained as 186 students out of 260 invited agreed to voluntarily participate in the study by filling out the questionnaires. 


\section{MEHDI SOLHI}

\section{Instruments}

\section{Coping with Boredom Scale (CBS)}

The CBS, originally designed by Nett et al. (2010), was administered to determine students' boredom coping strategies in the classroom. The scale possesses four subcategories: cognitive approach, behavioral approach, cognitive avoidance, and behavioral avoidance. The scale consists of 20 items in total with five items for each category (Appendix A). All of the items in the scale point to the experience of boredom in 'mathematics class'. For example, one of the cognitive approach items is "When I am bored in mathematics class, I tell myself to concentrate again". The term 'mathematics class' was substituted for the term 'in the classroom' and the modified version of the scale (Appendix B) was administered to the students in a varying number of courses in the department, ranging from reading skills, listening and pronunciation, and writing skills to approaches and methods in language teaching, linguistics, and language and culture. The students replied to the questionnaire on a 5 -point Likert-type scale ranging from 1 (strongly disagree) to 5 (strongly agree). The scale showed satisfactory descriptive statistics and internal consistency values of $.87, .86, .88$, and .83 for cognitive approach, behavioral approach, cognitive avoidance, and behavioral avoidance, respectively.

\section{The Multidimensional State Boredom Scale (MSBS)}

The MSBS was used to explore participants' multidimensional state boredom in the classroom. The scale was prepared by Fahlman et al. (2013). It consists of 29 items in total with a different number of items for each subscale (Appendix C). It contains measures for disengagement (10 items), high arousal (5 items), low arousal (5 items), inattention (4 items), and time perception (5 items). The students responded to the items of the MSBS on a 7-point Likert-type scale ranging from 1 (strongly disagree) to 7 (strongly agree). The coefficient alpha of the full scale of the MSBS was reported to range from .94 to .96. Exploring the utility of the MSBS, Hunter et al. (2015) used differential item functioning to identify if any items functioned differently for male and female participants. Despite obtaining a slightly higher mean score, the male participants $(\mathrm{M}=109.5)$ did not score significantly differently than the female participants $(M=107.6)$ on their general score on the scale, and this indicates that the MSBS's factor structure was invariant across gender.

\section{Results}

This study sought answers to two questions that explored university students' state boredom dimensions and their coping with boredom strategies along with measuring the effects of the mediating variables of gender and academic year. The state boredom dimensions were disengagement, high arousal, low arousal, inattention, and time perception. The coping strategies, as grouped in the questionnaire sub-scales, were cognitive approach, behavioral approach, cognitive avoidance, and behavioral avoidance.

At the outset, it was necessary to establish the reliability of the instruments used for data collection. The two instruments used for data collection purposes in this study were the coping strategies questionnaire with four sub-scales and the state boredom questionnaire with five sub-scales. The internal consistency reliability estimates of these questionnaires based on Cronbach's alpha test were $\alpha=.751$ for the Coping with Boredom Scale and $\alpha=.934$ for the Multidimensional State Boredom Scale.

For the first research question, it was firstly hypothesized that female students would report lower levels of boredom than the males in higher education, and thereby would be more likely to excel in coping with boredom in the classroom. At the outset, a t-test was conducted to explore whether there was any difference between male and female students with respect to their state boredom level and boredom coping strategies separately. Descriptive statistics for the two groups indicated that the male participants had a higher mean score for all the state boredom levels: disengagement $(\mathrm{M}=44.88, \mathrm{SD}=11.85)$, high arousal $(\mathrm{M}=20.07, \mathrm{SD}=5.90)$, low arousal $(M=19.43, S D=5.34)$, inattention $(M=16.98, S D=56.68)$, and time perception $(M=19.88, S D=5.35)$.

The results obtained from the t-test run (Table 1) indicated a significant difference between the scores of male and female participants in all of the state boredom dimensions: disengagement $t(184)=2.29, p>.023$, high arousal $t(184)=.62, p>.534$, and low arousal $t(184)=2.16, p>.032$, inattention $t(184)=4.66, p>.000$, and time perception $t(184)=3.23, p>.001$ 


\section{UNIVERSITY STUDENTS’ MULTIDIMENSIONAL STATE BOREDOM}

\section{Table 1}

T-test results between the male and the female groups'state boredom dimensions

\begin{tabular}{|c|c|c|c|c|c|c|}
\hline & & $\mathbf{F}$ & Sig. & $\mathbf{T}$ & Df & Sig. (2-tailed) \\
\hline \multirow[t]{2}{*}{ Disengagement } & Equal variances assumed & .16 & .68 & 2.29 & 184 & .023 \\
\hline & Equal variances not assumed & & & 2.30 & 90.82 & .024 \\
\hline \multirow[t]{2}{*}{ High Arousal } & Equal variances assumed & .88 & .34 & .62 & 184 & .534 \\
\hline & Equal variances not assumed & & & .60 & 85.98 & .544 \\
\hline \multirow[t]{2}{*}{ Low Arousal } & Equal variances assumed & .007 & .93 & 2.16 & 184 & .032 \\
\hline & Equal variances not assumed & & & 2.19 & 93.13 & .031 \\
\hline \multirow[t]{2}{*}{ Inattention } & Equal variances assumed & 26.72 & .000 & 4.66 & 184 & .000 \\
\hline & Equal variances not assumed & & & 3.85 & 66.19 & .000 \\
\hline \multirow[t]{2}{*}{ Time perception } & Equal variances assumed & .95 & .33 & 3.23 & 184 & .001 \\
\hline & Equal variances not assumed & & & 3.34 & 96.81 & .001 \\
\hline
\end{tabular}

Consequently, another t-test was carried out to investigate potential differences between the genders regarding their boredom coping strategies. Descriptive statistics for the two groups revealed that the male participants had a higher mean score for behavioral approach $(\mathrm{M}=11.98, \mathrm{SD}=4.45)$, while the mean score of the female participants was higher for cognitive approach $(\mathrm{M}=18.41, \mathrm{SD}=3.89)$. On the other hand, considering the avoidance strategies, the male participants exhibited a higher mean score than the female participants for cognitive avoidance $(\mathrm{M}=14.15, \mathrm{SD}=4.89)$, while that of the female participants was higher for behavioral avoidance $(\mathrm{M}=17.26, \mathrm{SD}=4.55)$.

The results obtained from the t-test run (Table 2) identified a significant difference between them for cognitive approach $t(184)=-2.32, p>.021$ and behavioral approach $t(184)=2.54 p>.012$. However, despite the differences in the means scores of the male and female participants, there was not a significant difference between them for avoidance strategies: cognitive avoidance $t(184)=1.64, p<.102$ and behavioral avoidance $t(184)=-1.42, p<$ .157

Table 2

T-test results between the male and the female groups' boredom coping strategies

\begin{tabular}{|c|c|c|c|c|c|c|}
\hline & & $\mathbf{F}$ & Sig. & $\mathbf{T}$ & df & Sig. (2-tailed) \\
\hline \multirow[t]{2}{*}{ Cognitive approach } & Equal variances assumed & 008 & .928 & -2.32 & 184 & .021 \\
\hline & Equal variances not assumed & & & -2.27 & 85.95 & .026 \\
\hline \multirow[t]{2}{*}{ Behavioral approach } & Equal variances assumed & 2.199 & .140 & 2.54 & 184 & .012 \\
\hline & Equal variances not assumed & & & 2.34 & 77.53 & .022 \\
\hline \multirow[t]{2}{*}{ Cognitive avoidance } & Equal variances assumed & 1.016 & .315 & 1.64 & 184 & .102 \\
\hline & Equal variances not assumed & & & 1.56 & 82.04 & .122 \\
\hline \multirow[t]{2}{*}{ Behavioral avoidance } & Equal variances assumed & 1.553 & .214 & -1.42 & 184 & .157 \\
\hline & Equal variances not assumed & & & -1.29 & 76.32 & .199 \\
\hline
\end{tabular}

In the final phase of the first research question, a regression was also run with gender as the predictor and total coping strategies as the outcome variables in SPSS 26. If gender had any significant effect, we could have predicted that it might mediate the effect of total coping strategies on total state boredom. Table 3 contains a report of the case summaries. It includes information about male and female students' means in relation to their state boredom and coping strategies. 


\section{MEHDI SOLHI}

\section{Table 3}

Male and female students' total state boredom and coping strategy scores

\begin{tabular}{lcc}
\hline Gender & Total State Boredom & Total Coping Strategy \\
\hline Male & 121.2549 & 59.1765 \\
Female & 107.3333 & 58.9630 \\
Total & $\mathbf{1 1 1 . 1 5 0 5}$ & $\mathbf{5 9 . 0 2 1 5}$ \\
\hline
\end{tabular}

The results indicated that while the general mean scores of male and female students' coping strategies were not very different from each other (59.17 vs. 58.96), their state boredom means (121.26 vs. 107.33) differed significantly. This difference might suggest that gender could be mediating the relationship between state boredom and coping strategies. The regression tables would categorically show if this is the case.

A model summary (Table 4) is a summary of the regression results. R and R-squared in this table show the correlation between the observed and predicted values of the outcome variable and the amount of variance explained by the model, respectively. As can be seen, the amount of explained variance is noticeable.

\section{Table 4}

Model summary

\begin{tabular}{ccccc}
\hline Model & R & R-Squared & Adjusted R-Squared & Std. Error of the Estimate \\
\hline 1 & $.202^{\mathrm{a}}$ & .041 & .036 & 30.28036 \\
\hline
\end{tabular}

Note. a. Predictors: (Constant), gender

Evidently, there has been an effect for the predictor variable and since there is just one predictor variable, namely gender, we can attribute this effect totally to this variable. This is a conclusion reflected in coefficients table (Table 6) that follows the ANOVA analysis (Table 5).

\section{Table 5}

ANOVA showing the effect of the predictor variable

\begin{tabular}{lccccc}
\hline \multicolumn{1}{c}{ Model } & Sum of Squares & Df & Mean Square & F & Sig. \\
\hline Regression & 7174.099 & 1 & 7174.099 & 7.824 & $.006^{\mathrm{b}}$ \\
Residual & 168709.686 & 184 & 916.900 & & \\
Total & $\mathbf{1 7 5 8 8 3 . 7 8 5}$ & $\mathbf{1 8 5}$ & & & \\
\hline
\end{tabular}

Note. a. Dependent Variable: Total State Boredom. b. Predictors: (Constant), gender.

Beta in the coefficients table is especially important because it indicates the degree of change in the outcome variable per unit of change in the predictor variable. In other words, for each unit of change in the gender of the participants (from male to female), it is predicted that state boredom would reduce .202\% of a unit (Table 6).

\section{Table 6}

Coefficients

\begin{tabular}{lccccc}
\hline \multirow{2}{*}{ Model } & \multicolumn{2}{c}{ Unstandardized Coefficients } & Standardized Coefficients & \multirow{2}{*}{ T } & \multirow{2}{*}{ Sig. } \\
\cline { 2 - 4 } & $\mathbf{B}$ & std. Error & Beta & & 15.237 \\
\hline (Constant) & 135.176 & 8.872 & & .000 \\
Gender & -13.922 & 4.977 & -.202 & -2.797 & .006 \\
\hline
\end{tabular}

Note. a. Dependent Variable: Total State Boredom 
In the second research question, it was firstly hypothesized that the more advanced the students are in their academic studies, the better they would be able to cope with their state boredom. To this end, it was firstly explored whether the students' academic year (i.e., freshman, sophomore, junior, and senior) affected their boredom level distinctly. As Table 7 indicates, the results obtained from the one-way ANOVA for the disengagement revealed a significant difference among the scores of the freshmen $(M=42.50, S D=13.32)$, sophomores $(\mathrm{M}=42.93, \mathrm{SD}=10.15)$, juniors $(\mathrm{M}=37.51, \mathrm{SD}=11.29)$, and seniors $(\mathrm{M}=34.77, \mathrm{SD}=14.51), F(3$, $182)=2.31, p<.05$. However, in respect to high arousal, there was not a significant difference among the scores of the freshmen $(M=19.94, S D=6.49)$, sophomores $(M=20.30, S D=4.95)$, juniors $(M=18.98, S D=5.03)$, and seniors $(\mathrm{M}=18.55, \mathrm{SD}=6.88), F(3,182)=.77, p>.05$. Nor was there a significant difference for low arousal among the freshmen $(\mathrm{M}=14.35, \mathrm{SD}=6.18)$, sophomores $(\mathrm{M}=14.45, \mathrm{SD}=5.15)$, juniors $(\mathrm{M}=14.13, \mathrm{SD}=4.48)$, and seniors $(\mathrm{M}=12.72, \mathrm{SD}=5.51), F(3,182)=.69, p>.05$. The inattention of the participants similarly did not exhibit a significant difference among the freshmen $(M=18.48, S D=6.17)$, sophomores $(M=18.28, S D=4.73)$, juniors $(\mathrm{M}=17.75, \mathrm{SD}=5.27)$, and seniors $(\mathrm{M}=16.44, \mathrm{SD}=6.81), F(3,182)=.51, p>.05$. Finally, similar to the other state boredom dimensions, the participants' time perception did not indicate a significant difference among the mean scores of the freshmen $(M=17.53, S D=5.90)$, sophomores $(M=17.68, S D=5.59)$, juniors $(M=$ $18.34, \mathrm{SD}=6.09)$, and seniors $(\mathrm{M}=16.33, \mathrm{SD}=5.67), F(3,182)=.55, p>.05$. Indeed, apart from disengagement, no dimensions of the state boredom exhibited any significant difference among the participants with different academic levels.

\section{Table 7}

One-way ANOVA for the academic level in respect to state boredom dimensions

\begin{tabular}{|c|c|c|c|c|c|c|}
\hline & & Sum of Squares & df & Mean Square & $\mathbf{F}$ & Sig. \\
\hline \multirow[t]{3}{*}{ Disengagement } & Between Groups & 990.07 & 3 & 330.02 & 2.31 & .05 \\
\hline & Within Groups & 25935.82 & 182 & 142.50 & & \\
\hline & Total & 26925.89 & 185 & & & \\
\hline \multirow[t]{3}{*}{ High arousal } & Between Groups & 75.11 & 3 & 25.03 & .77 & .50 \\
\hline & Within Groups & 5870.86 & 182 & 32.25 & & \\
\hline & Total & 5945.97 & 185 & & & \\
\hline \multirow[t]{3}{*}{ Low arousal } & Between Groups & 64.59 & 3 & 21.53 & .69 & .55 \\
\hline & Within Groups & 5628.36 & 182 & 30.92 & & \\
\hline & Total & 5692.95 & 185 & & & \\
\hline \multirow[t]{3}{*}{ Inattention } & Between Groups & 44.45 & 3 & 14.81 & .51 & .67 \\
\hline & Within Groups & 5213.37 & 182 & 28.64 & & \\
\hline & Total & 5257.83 & 185 & & & \\
\hline \multirow[t]{3}{*}{ Time perception } & Between Groups & 56.85 & 3 & 18.95 & .55 & .64 \\
\hline & Within Groups & 6206.68 & 182 & 34.10 & & \\
\hline & Total & 6263.53 & 185 & & & \\
\hline
\end{tabular}

Additionally, the effect of the students' academic level on their boredom coping strategies was taken into scrutiny. The results obtained from the one-way ANOVA for the cognitive approach exhibited a significant difference among the scores of the freshmen $(\mathrm{M}=19.17, \mathrm{SD}=3.00)$, sophomores $(\mathrm{M}=18.11, \mathrm{SD}=4.53)$, juniors $(\mathrm{M}=16.55, \mathrm{SD}=3.93)$, and seniors $(\mathrm{M}=18.11, \mathrm{SD}=4.01), F(3,182)=4.09, p<.05$. In respect to the behavioral approach, however, there was not a significant difference among the mean score of the freshmen $(\mathrm{M}=10.76$, SD = 3.49), sophomores $(\mathrm{M}=11.15, \mathrm{SD}=4.50)$, juniors $(\mathrm{M}=10.13, \mathrm{SD}=3.52)$, and seniors $(\mathrm{M}=11.55, \mathrm{SD}=4.80), F(3$, $182)=.854, p>.05$ (Table 8$)$.

\section{Table 8}

One-way ANOVA for the academic level in respect to the strategic approach to cope with boredom

\begin{tabular}{|c|c|c|c|c|c|c|}
\hline & & Sum of Squares & df & Mean Square & $\mathbf{F}$ & Sig. \\
\hline \multirow[t]{3}{*}{ Cognitive approach } & Between Groups & 186.99 & 3 & 62.33 & 4.09 & .008 \\
\hline & Within Groups & 2773.00 & 182 & 15.23 & & \\
\hline & Total & 2960.00 & 185 & & & \\
\hline \multirow[t]{3}{*}{ Behavioral approach } & Between Groups & 40.68 & 3 & 13.56 & .854 & .466 \\
\hline & Within Groups & 2890.13 & 182 & 15.88 & & \\
\hline & Total & 2930.82 & 185 & & & \\
\hline
\end{tabular}

Similar to the behavioral approach to cope with boredom, the results of the one-way ANOVA for cognitive avoidance indicated no significant difference among the scores of the freshmen $(\mathrm{M}=12.37, \mathrm{SD}=4.76)$, 
sophomores $(\mathrm{M}=13.43, \mathrm{SD}=4.24)$, juniors $(\mathrm{M}=14.32, \mathrm{SD}=4.43)$, and seniors $(\mathrm{M}=12.44, \mathrm{SD}=4.84), F(3,182)=$ $1.909, p>.05$. Nor was there a significant difference among the mean score of the freshmen $(\mathrm{M}=16.73, \mathrm{SD}=$ 4.53), sophomores $(\mathrm{M}=16.16, \mathrm{SD}=5.56)$, juniors $(\mathrm{M}=18.07, \mathrm{SD}=4.27)$, and seniors $(\mathrm{M}=17.11, \mathrm{SD}=4.86), F(3$, $182)=1.497, p>.05$ with regard to behavioral avoidance. Indeed, neither cognitive avoidance nor behavioral avoidance exhibited a significant difference among the participants with different educational levels (Table 9).

\section{Table 9}

One-way ANOVA for the academic level in respect to strategic avoidance to cope with boredom

\begin{tabular}{|c|c|c|c|c|c|c|}
\hline & & Sum of Squares & df & Mean Square & $\mathbf{F}$ & Sig. \\
\hline \multirow[t]{3}{*}{ Cognitive avoidance } & Between Groups & 116.81 & 3 & 38.93 & 1.909 & .130 \\
\hline & Within Groups & 3711.74 & 182 & 20.39 & & \\
\hline & Total & 3828.55 & 185 & & & \\
\hline \multirow[t]{3}{*}{ Behavioral avoidance } & Between Groups & 105.95 & 3 & 35.31 & 1.497 & .217 \\
\hline & Within Groups & 4294.78 & 182 & 23.59 & & \\
\hline & Total & 4400.73 & 185 & & & \\
\hline
\end{tabular}

\section{Discussion}

The purpose of this study was twofold: At the outset, gender-mediated relationship between university students' state boredom dimensions and their coping with boredom strategies were explored. The descriptive statistics for the two groups revealed that the male participants scored significantly higher than the female students, indicating that the male participants experienced significantly higher levels of boredom than their counterparts in all levels of the state boredom (i.e., disengagement, high arousal, low arousal, inattention, and time perception). As the male participants reported significantly in all dimensions of state boredom, they were more likely to find the lessons repetitive, longing for something more exciting (disengagement), find the classroom lectures more irritating while feeling more impatient (high arousal), feel down and empty (low arousal), feel easily distracted (inattention), and wish time would go by faster (time perception) than the female students in university. Indeed, the significant difference in the mean scores of these subcategories reveals that the male participants had greater difficulty, say, devoting attention to the lessons than the females in the classroom. In addition, the male participants were more likely to feel that time passes more slowly for them contrary to the female individuals. This type of perception of time is categorized as a cognitive component of boredom, in which time tends to seem to pass far slower for the bored students in the classroom (Nett et al., 2011). In line with the present study findings, in Vodanovich et al.'s (2011) investigation, the male students reported significantly higher scores in perception of time.

Eastwood et al. (2012) asserted that an individual's emotions can fluctuate between low and high arousal negative affect during a particular situation of boredom. Specifically, the male participants exhibited higher levels of boredom in terms of low and high arousal in the classroom. Identifying that a student experiences a low or high arousal negative affect in the classroom could be important for recognizing and responding to boredom (Hunter et al., 2015) as different cognitive impairments could be associated with each particular type of boredom (Malkovsky et al., 2012).

The finding that, overall, male students significantly experienced higher levels of boredom than females could be related to different factors, such as males' greater desire for various external stimulation, as they tend to demonstrate a stronger need for additional incentives than females (Vodanovich \& Kass, 1990). The current study's results are also in line with Von Gemmingen et al. (2003) and Vodanovich et al.'s, (2011) findings in which male students reported significantly higher levels of boredom proneness than female students, and they reported higher mean boredom proneness in terms of external stimulation, respectively.

Indeed, the individuals' inattention in the classroom triggered by boredom has been shown to affect their achievement scores in school. Eren and Coskun's (2016) study on high school students' intermediary functions of boredom managing strategies and epistemic curiosity in the relationship between their level of boredom and achievement scores also revealed that interest-type and deprivation-type epistemic curiosity played significant mediating roles in the relationship between the level of boredom and achievement scores, and differed across gender, indicating that the achievement scores of female students were significantly higher than those of male 
students. Indeed, Eren and Coskun's study's results imply that female students experience lower levels of boredom than male students and this can lead to higher achievement scores in school. Although Eren and Coskun's findings are echoed in the present study with respect to the lower boredom experience of female participants, the difference in the participants' achievement scores were not the focus of the present study.

After exploring the differences between male and female participants' state boredom dimensions, and identifying that the male participants experienced more trouble giving their attention to the lessons and exhibited more difficulty perceiving time than the females in the classroom, in the second phase of the first research question, the possible differences between the male and female participants with respect to their boredom coping strategies in the classroom were scrutinized. The results indicated that the male students had a significantly higher mean score in behavioral approach, while the mean score of the female participants was significantly higher in cognitive approaches for coping with boredom, indicating that the male and female participants exhibited different cognitive and behavioral approaches to cope with boredom. On the other hand, with respect to the avoidance strategies, the male participants had a slightly higher mean score than the female participants in cognitive avoidance, while the female participants had higher mean score in behavioral avoidance. However, despite the slight differences in the means scores of the male and female participations, the results did not identify significant differences in terms of the cognitive or behavioral avoidance strategies for dealing with boredom.

As mentioned earlier, individuals adopting the behavioral approach to cope with boredom tend to fundamentally change the exhausting situations. Based on the results, the behavioral reactions (i.e., approach) of the male participants to cope with the boredom were significantly higher than the females. In fact, the male students were likely to employ more behavioral approaches than the female participants by directly asking the instructor to substitute the current tasks in the classroom with more interesting activities. Conversely, individuals adopting cognitive approaches to deal with boredom may employ strategies to change the perception of the situation rather than exhibit behavioral reactions to boring situations. In this study, since the female participants employed more cognitive approach strategies than the male participants, they might cope with a boring situation cognitively by keeping silent and reminding themselves that the current lesson, despite being boring, is important and needs their full attention.

In contrast to the male participants' inclination to exploit the behavioral approach rather than the cognitive approach when dealing with boredom, they interestingly exhibited a tendency to employ cognitive avoidance more than female participants. This means that male students are more likely to occupy their thoughts with something seemingly more interesting and probably avoid the lesson in the classroom by doodling or daydreaming as a strategy to disregard the boring situation cognitively. In fact, in connection with the findings that the male participants' boredom can lead to greater disengagement and emotional arousal, as well as lower time perception and failure to pay attention, it might be concluded that classroom boredom makes male students inattentive and less tolerant toward class time, and this can eventually make them exhibit the behavioral approach or cognitive avoidance to alleviate boredom experiences in the classroom. In Eren's (2013) study, different aspects of engagement were reported to be significantly interrelated with boredom coping strategies except cognitive avoidance orientation. Indeed, it indicates that the male participants with slightly a higher proportion of employing cognitive avoidance to cope with boredom were less likely to be effectively engaged in classroom language learning. The results of this study aligned with those of Nett et al.'s (2011) study in that the cognitive approach orientation was similarly identified with smaller degree of boredom.

In addition to the inclination to use significantly more cognitive approach strategies, the female participants indicated slightly, however not significantly, more tendencies to use behavioral avoidance to avoid the exhausting situations. Specifically, the findings implied that students might divert attention away from boring situations by chatting with a classmate during the lesson, texting, playing games on the cellphone as behavioral avoidance strategies to evade the boring situations in the classroom. In Zhou and Kam's (2017) study, behavioral avoidance was also reported to significantly predict procrastination.

In the second research question, an attempt was made to investigate whether there was a grade-mediated relationship between students' state boredom dimensions and coping with boredom strategies. In so doing, at the outset, the researcher explored whether the students' academic year (i.e., freshman, sophomore, junior, or senior) affected their boredom level distinctly. In fact, different from Pawlak et al.'s (2020) study in which the 


\section{MEHDI SOLHI}

sophomores experienced more boredom during practical English classes than the juniors, in this study, no dimensions of the state boredom except disengagement exhibited any significant differences among the participants with different academic levels. This dimension of boredom was shown to be significantly different according to the students' academic year. Specifically, freshmen and sophomores exhibited higher levels of boredom than juniors and seniors, and this likely led to their disengagement in the classroom. In Pawlak et al.'s (2020) study, meaningful differences were similarly identified between the boredom experiences of sophomores and juniors in relation to their perception of the passing of time. As mentioned earlier, the time perception was similarly identified to be different for the males and females in this study.

Additionally, the effect of the students' academic level on their boredom coping strategies was scrutinized. While the cognitive approach exhibited a significant difference among the participants from different educational levels, they did not score significantly differently for the behavioral approach. This means that the participants' educational level was a determining factor in using cognitive approaches to cope with boredom in the classroom. Specifically, the freshmen group used the cognitive approach more than the other groups, while the senior group was reported to employ the cognitive approach the least in comparison with the other groups to deal with boredom in the classroom. These findings can be attributed to the fact that the freshmen possessed the least amount of experience in higher education, and thereby tended to convince themselves that the lessons, although boring, were of importance and deserved more attention, rather than using behavioral approaches to cope with boredom. Similar to the behavioral approach to cope with boredom, neither cognitive avoidance nor behavioral avoidance exhibited a significant difference among the participants with different educational levels. This means that the university students' academic level was not a determining factor in exploiting either cognitive avoidance or behavioral avoidance to cope with boredom in the classroom.

\section{Conclusion}

Tze et al.'s (2015) meta-analysis study on the relationship between boredom and academic achievements indicated that classroom boredom can have a stronger negative influence on students' academic achievements than the boredom they experience when studying. Indeed, the present study highlights the significance of identifying student boredom in the classroom in order to specify strategies to mitigate their boredom in academic milieus in general and classrooms in particular. The conclusions drawn from the findings suggest that university students' boredom and their boredom coping strategies need to be closer scrutiny. By gaining a proper understanding of the reactions triggered by boredom in classes, we would be able to spot the developmental paths of these reactions and thereby adopt the necessary measures to deal with their boredom experiences. As mentioned earlier, Mann and Robinson's (2009) study indicated that the nature of courses and the lectures in higher education can impact the students' classroom boredom. Their study provides insight into the fact that learner involvement and collaborative learning need to be thoroughly integrated in the process of learning so as to mitigate boredom experiences in the classroom.

By virtue of the fact that students who effectively manage boredom might be more high-achieving in school, feel more joy and self-confidence, and be more satisfied (Nett et al., 2010), familiarizing the students with the effectiveness of cognitive approach strategies, and using them to effectively reduce feelings of boredom can improve motivation and attainment, and consequently promote a more pleasant learning experience for both learners and instructors alike in the classroom (Nett et al., 2011). It is worth pointing out that one of the limitations of this study was the sample size, from which it could be difficult to generalize the results obtained. Likewise, the courses in the English language teaching department could also be seen as a limitation, given that they all belong to a particular department (i.e., English language teaching) in a university. Utilizing a larger sample size from several university faculties would surely increase the generalizability of the findings. Thus, future studies would be well advised to include larger samples to replicate these findings. The university students' age as a mediating factor and the effect of their personality traits such as intelligence on their boredom management in the classroom also appear to be fruitful avenues for future research.

\section{References}

Acee, T. W., Kim, H., Kim, H. J., Kim, J., Chu, H. R., Kim, M., .Cho, Y., Wicker, F.W., \& The Boredome research group. 
(2010). Academic boredom in under- and over-challenging situations. Contemporary Educational Psychology, 35(1), 17-27. https://doi.org/10.1016/j.cedpsych.2009.08.002

Ahmed, W., van der Werf, G., Kuyper, H., \& Minnaert, A. (2013). Emotions, self-regulated learning, and achievement in Mathematics: A growth curve analysis. Journal of Educational Psychology, 105(1), 150-161. https://psycnet.apa.org/doi/10.1037/a0030160

Altintas, E., Karaca, Y., Moustafa, A., \& El Haj, M. (2020). Effect of best possible self intervention on situational motivation and commitment in academic context. Learning and Motivation, 69, 1-7. https://psycnet.apa.org/ doi/10.1016/j.lmot.2019.101599

Beiter, R., Nash, R., McCrady, M., Rhoades, D., Linscomb, M., Clarahan, M., \& Sammut, S. (2015). The prevalence and correlates of depression, anxiety, and stress in a sample of college students. Journal of Affective Disorders, 173(1), 90-96. https://doi.org/10.1016/j.jad.2014.10.054

Brown, H. D. (2014). Principles of language learning and teaching: A course in second language acquisition (6th edition). Pearson Education, Inc.

Busari, A. O. (2018). Motivation, stress, anxiety and emotions as predictors of academic boredom among degree students of National Teachers' Institute Osogbo, Osun State, Nigeria. World Scientific News, 112, 158-172.

Daniels, L. M., Tze, V. M. C., \& Goetz, T. (2015). Examining boredom: Different causes for different coping profiles. Learning and Individual Differences, 37(1), 255-261. https://psycnet.apa.org/doi/10.1016/j.lindif.2014.11.004

Daschmann, E. C., Goetz, T., \& Stupnisky, R. H. (2011). Testing the predictors of boredom at school: Development and validation of the precursors to boredom scales. British Journal of Educational Psychology, 81(3), 421-440. https://doi.org/10.1348/000709910x526038

Deng, Y., Chang, L., Yang, M., Huo, M., \& Zhou, R. (2016). Gender differences in emotional response: Inconsistency between experience and expressivity. PLOS ONE, 11(6), 1-12. https://psycnet.apa.org/doi/10.1371/journal. pone. 0158666

Eastwood, J. D., Frischen, A., Fenske, M. J., \& Smilek, D. (2012). The unengaged mind: Defining boredom in terms of attention. Perspectives on Psychological Science, 7(5), 482-495. https://psycnet.apa.org/ doi/10.1177/1745691612456044

Eren, A. (2013). Prospective teachers' perceptions of instrumentality, boredom coping strategies, and four aspects of engagement. Teaching Education, 24(3), 302-326. https://doi.org/10.1080/10476210.2012.724053

Eren, A., \& Coskun, H. (2016). Students' level of boredom, boredom coping strategies, epistemic curiosity, and graded performance. The Journal of Educational Research, 109(6), 574-588. https://doi.org/10.1080/0022067 1.2014 .999364

Fahlman, F. S., Mercer-Lynn, K. B., Flora, D. B., \& Eastwood, J. D. (2013). Development and validation of the multidimensional state boredom scale. Assessment, 20(1), 68-85. https://doi.org/10.1177/1073191111421303

Farmer, R., \& Sundberg, N. D. (1986). Boredom proneness: The development and correlates of a new scale. Journal of Personality Assessment, 50(1), 4-17. https://psycnet.apa.org/doi/10.1207/s15327752jpa5001_2

Fernández-Río, J., Cecchini, J. A., \& Méndez-Giménez, A. (2014). Effects of cooperative learning on perceived competence, motivation, social goals, effort and boredom in prospective Primary Education teachers. Journal for the Study of Education and Development, 37(1), 57-89. https://doi.org/10.1080/02103702.2014.881650

Finkielsztein, M. (2019). Class-related academic boredom among university students: A qualitative research on boredom coping strategies. Journal of Further and Higher Education, 44(8), 1098-1113. https://doi.org/10.108 0/0309877X.2019.1658729

Fischer, A. H., Kret, M. E., \& Broekens, J. (2018). Gender differences in emotion perception and self-reported emotional intelligence: A test of the emotion sensitivity hypothesis. PLoS ONE, 13(1), 1-19. https://doi. org/10.1371/journal.pone.0190712

Fisher, C. D. (1993). Boredom at work: A neglected concept. Human Relations, 46(3), 395-417. https://psycnet.apa. org/doi/10.1177/001872679304600305

Goetz, T., Frenzel, A.C., Hall, N.C., Nett, U., Pekrun, R., \& Lipnevich, A. (2014). Types of boredom: An experience sampling approach. Motivation and Emotion, 50, 401-419. https://doi.org/10.1007/s11031-013-9385-y

Hill, A. B. \& Perkins, R. E. (1985). Towards a model of boredom. British Journal of Psychology, 76, 235-240. https:// doi.org/10.1111/j.2044-8295.1985.tb01947.x

Hunter, J. A., Dyer, K. J., Cribbie, R. A., \& Eastwood, J. D. (2015). Exploring the utility of the multidimensional state boredom scale. European Journal of Psychological Assessment, 32(3), 241-250. https://psycnet.apa.org/ doi/10.1027/1015-5759/a000251

Iso-Ahola, S. E., \& Weissinger, E. (1987). Leisure and boredom. Journal of Social and Clinical Psychology, 5(3), 356364. https://psycnet.apa.org/doi/10.1521/jscp.1987.5.3.356

Jarvis, S., \& Seifert, T. (2002). Work avoidance as a manifestation of hostility, helplessness, and boredom. Alberta 


\section{MEHDI SOLHI}

Journal of Education Research, 48(2), 174-187.

Le, B. M., \& Impett, E. A. (2013). When holding back helps: Suppressing negative emotions during sacrifice feels authentic and is beneficial for highly interdependent people. Psychological Science, 24(9), 1809-1815. https:// doi.org/10.1177\%2F0956797613475365

Lerner, R.E., \& Grolnick, W.S. (2020). Maternal involvement and children's academic motivation and achievement: The roles of maternal autonomy support and children's affect. Motivation and Emotion, 44, 373-388. https:// doi.org/10.1007/s11031-019-09813-6

Lichtenfeld, S., Pekrun, R., Stupnisky, R. H., Reiss, K., \& Murayama, K. (2012). Measuring students' emotions in the early years: The Achievement Emotions Questionnaire-Elementary School (AEQ-ES). Learning and Individual Differences, 22(2), 190-201. https://psycnet.apa.org/doi/10.1016/j.lindif.2011.04.009

Malkovsky, E., Merrifield, C., Goldberg, Y., \& Danckert, J. (2012). Exploring the relationship between boredom and sustained attention. Experimental Brain Research, 221, 59-67. https://doi.org/10.1007/s00221-012-3147-z

Mann, S., \& Robinson, A. (2009). Boredom in the lecture theatre: an investigation into the contributors, moderators and outcomes of boredom amongst university students. British Educational Research Journal, 35(2), 243-258. https://doi.org/10.1080/01411920802042911

Mikulas, W. L., \& Vodanovich, S. J. (1993). The essence of boredom. Psychological Record, 43(1), 3-12.

Muramatsu, K., Tanaka, E., Watanuki, K., \& Matsui, T. (2016). Framework to describe constructs of academic emotions using ontological descriptions of statistical models. Research and Practice in Technology Enhanced Learning, 11(5), 1-18. https://doi.org/10.1186/s41039-016-0029-1

Nett, U. E., Goetz, T., \& Daniels, L. M. (2010). What to do when feeling bored? Students' strategies for coping with boredom. Learning and Individual Differences, 20, 626-638. https://psycnet.apa.org/doi/10.1016/j. lindif.2010.09.004

Nett, U. E., Goetz, T., Hall, N. C. (2011). Coping with boredom in school: An experience sampling perspective. Contemporary Educational Psychology, 36, 49-59. https://psycnet.apa.org/doi/10.1016/j.cedpsych.2010.10.003

Neu, J. (1998). Boring from within: Endogenous versus reactive boredom. In W. F. Flack, \& J. D. Laird (Eds.), Emotions in Psychopathology: Theory and research (pp. 158-170). Oxford University Press.

Nezlek, J. B., \& Kuppens, P. (2008). Regulating positive and negative emotions in daily life. Journal of Personality, 76(3), 561-580. https://doi.org/10.1111/j.1467-6494.2008.00496.x

Pawlak, M., Zawodniak, J., \& Kruk, M. (2020). The neglected emotion of boredom in teaching English to advanced learners. International Journal of Applied Linguistics, 30(3), 497-505. https://doi.org/10.1111/ijal.12302

Pekrun, R. (2006). The control-value theory of achievement emotions: Assumptions, corollaries, and implications for educational research and practice. Educational Psychology Review, 18, 315-341. https://doi.org/10.1007/ s10648-006-9029-9

Pekrun, R., Goetz, T., Daniels, L. M., Stupnisky, R. H., \& Perry, R. P. (2010). Boredom in achievement settings: Exploring control-value antecedents and performance outcomes of a neglected emotion. Journal of Educational Psychology, 102(3), 531-549. https://doi.org/10.1037/A0019243

Pekrun, R., Goetz, T., Frenzel, A. C., Barchfeld, P., \& Perry, R. P. (2011). Measuring emotions in students' learning and performance: The Achievement Emotions Questionnaire (AEQ). Contemporary Educational Psychology, 36(1), 36-48. https://psycnet.apa.org/doi/10.1016/j.cedpsych.2010.10.002

Pekrun, R., Goetz, T., Titz, W., \& Perry, R. P. (2002). Academic emotions in students' self-regulated learning and achievement: A program of qualitative and quantitative research. Educational Psychologist, 37(2), 91-105. https://psycnet.apa.org/doi/10.1207/S15326985EP3702_4

Pekrun, R., Hall, N. C., Goetz, T., \& Perry, R. P. (2014). Boredom and academic achievement: Testing a model of reciprocal causation. Journal of Educational Psychology, 106(3), 696-710. https://psycnet.apa.org/doi/10.1037/ a0036006

Puthran, R., Zhang, M. W., Tam, W. W., \& Ho, R. C. (2016). Prevalence of depression amongst medical students: A meta-analysis. Medical Education in Review, 50(4), 456-468. https://doi.org/10.1111/medu.12962

Raccanello, D., Brondino, M., Moè, A., Stupnisky, R., \& Lichtenfeld, S. (2018): Enjoyment, boredom, anxiety in elementary schools in two domains: Relations with achievement. The Journal of Experimental Education, 87(3), 449-469. https://doi.org/10.1080/00220973.2018.1448747

Respondek, L., Seufert, T., Stupnisky, R., \& Nett, U.E. (2017). Perceived academic control and academic emotions predict undergraduate university student success: Examining effects on dropout intention and achievement. Frontiers in Psychology, 8(243), 1-18. https://doi.org/10.3389/fpsyg.2017.00243

Ruan, Y., Reis, H.T., Zareba, W., \& Lane, R. D. (2020). Does suppressing negative emotion impair subsequent emotions? Two experience sampling studies. Motivation and Emotion, 44, 427-435. https://doi.org/10.1007/ s11031-019-09774-w 
Russell, R. V. (1996). Pastimes: The context of contemporary leisure. Brown \& Benchmark.

Schutz, P. A., \& DeCuir, J. T. (2002). Inquiry on emotions in education. Educational Psychologist, 37(2), 125-134. https://psycnet.apa.org/doi/10.1207/S15326985EP3702_7

Sharp, J. G., Hemmings, B., Kay, R., Murphy, B., \& Elliott, S. (2016). Academic boredom among students in higher education: A mixed-methods exploration of characteristics, contributors and consequences. Journal of Further and Higher Education, 45(5), 657-677. https://doi.org/10.1080/0309877X.2016.1159292

Sharp, J. G., Sharp, J. C., \& Young, E. (2020). Academic boredom, engagement and the achievement of undergraduate students at university: A review and synthesis of relevant literature. Research Papers in Education, 35(2), 144-184. https://doi.org/10.1080/02671522.2018.1536891

Shehzad, M. W., Ahmed, R., Razzaq, S., Akhtar, A., \& Hasan, M. K. (2020). Do reading boredom and reading boredom coping strategies predict reading comprehension performance? An empirical investigation of Saudi EFL learners. Indonesian Journal of Applied Linguistics, 10(2), 447-461.https://doi.org/10.17509/ijal. v10i2.28616

Shields, S. A. (2013). Gender and emotion: What we think we know, what we need to know, and why it matters. Psychology of Women Quarterly, 37(4), 423-435. https://psycnet.apa.org/doi/10.1177/0361684313502312

Sundberg, N. D., Latkin, C. A., Farmer, R. F., \& Saoud, J. (1991). Boredom in young adults: Gender and cultural comparisons. Journal of Cross-Cultural Psychology, 22(2), 209-223. https://psycnet.apa.org/ doi/10.1177/0022022191222003

Tze, V. M. C. (2011). Investigating academic boredom in Canadian and Chinese students [Unpublished master's thesis]. The University of Alberta.

Tze, V. M. C., Daniels, L. M., \& Klassen, R. M. (2015). Evaluating the relationship between boredom and academic outcomes: A meta-analysis. Educational Psychology Review, 28(1), 119-144. https://psycnet.apa. org/doi/10.1007/s10648-015-9301-y

Tze, V. M. C., Klassen, R. M., \& Daniels, L. M. (2014). Patterns of boredom and its relationship with perceived autonomy support and engagement. Contemporary Educational Psychology, 39(3), 175-187. https://psycnet. apa.org/doi/10.1016/j.cedpsych.2014.05.001

Vodanovich, S. J., \& Kass, S. J.(1990). A factor analytic study of the boredom proneness scale. Journal of Personality Assessment, 55(1), 115-123. https://psycnet.apa.org/doi/10.1207/s15327752jpa5501\&2_11

Vodanovich, S. J., Kass, S. J., Andrasik, F., Gerber, W. D., Niederberger, U., \& Breaux, C. (2011). Culture and gender differences in boredom proneness. North American Journal of Psychology, 13(2), 221-230.

Vodanovich, S. J., Verner, K. M., \& Gilbride, T. V. (1991). Boredom proneness: Its relationship between positive and negative affect. Psychological Reports, 69(3), 1139-1146. 10.2466/pr0.1991.69.3f.1139

Von Gemmingen, M. J., Sullivan, B. F., \& Pomerantz, A. M. (2003). Investigating the relationships between boredom proneness, paranoia, and self-consciousness. Personality \& Individual Differences, 34(6), 907-919. https://psycnet.apa.org/doi/10.1016/S0191-8869(01)00219-7

Wang, N., Wilhite, S. C., Wyatt, J., Young, T., \& Bloemker, G. (2012). Impact of a college freshman social and emotional learning curriculum on student learning outcomes: An exploratory study. Journal of University Teaching \& Learning Practice, 9(2), 1-20.

Wegner, L., Flisher, A.J., Chikobvu, P., Lombard, C., \& King, G. (2008). Leisure boredom and high school dropout in Cape Town, South Africa. Journal of Adolescence, 31, 421-431. 10.1016/j.adolescence.2007.09.004

Wood, J. V., Heimpel, S. A., \& Michela, J. L. (2003). Savoring versus dampening: Self-esteem differences in regulating positive affect. Journal of Personality and Social Psychology, 85(3), 566-580. https://psycnet.apa. org/doi/10.1037/0022-3514.85.3.566

Wyatt, J. B., \& Bloemker, G. A. (2013). Social and emotional learning in a freshman seminar. Higher Education Studies, 3(1), 106-114. http://dx.doi.org/10.5539/hes.v3n1p106

Yeung, D. Y., \& Fung, H. H. (2012). Impacts of suppression on emotional responses and performance outcomes: An experience-sampling study in younger and older workers. Journals of Gerontology. Series B, Psychological Sciences and Social Sciences, 67(6), 666-676. https://doi.org/10.1093/geronb/gbr159

Yule, G. (2014). The study of language ( th $^{\text {th }}$ ed.). Cambridge University Press.

Zhou, M., \& Kam, C. C. S. (2017). Trait procrastination, self-efficacy and achievement goals: The mediation role of boredom coping strategies. Educational Psychology, 37(7), 854-872. https://psycnet.apa.org/doi/10.1080/0 1443410.2017.1293801 


\section{Appendix A}

\section{Original items of the Coping with Boredom Scale}

\section{Cognitive approach}

When I am bored in mathematics class...

1) ...I try to pay attention to the lesson more.

2) ...I tell myself to concentrate again.

3) ...I make myself aware of the importance of the issue.

4) ...I try to make myself aware that this class is important.

5) ...I make myself focus again because the issue is important.

\section{Behavioral approach}

When I am bored in mathematics class...

1)...I ask my instructor if we can do something else.

2) ...I ask my instructor for more interesting tasks.

3) ...I suggest that the instructor add variety to the lessons.

4) ...I try to get the instructor off topic so that we discuss an issue that interests me.

5) ...I bring up an issue that I think the class is more interested in.

\section{Cognitive avoidance}

When I am bored in mathematics class...

1)...I prepare for my next class.

2)...I do my homework.

3) ...I study for another subject.

4) ...I think about my homework or something I have to study.

5) ...I copy the homework for my next class.

\section{Behavioral avoidance}

When I am bored in mathematics class...

1)...I talk to the person sitting next to me.

2) ...I start talking to my classmate sitting next to me.

3) ...I distract myself by interacting with my classmates.

4) ...I try to contact other classmates who are feeling also bored.

5) ...I occupy myself with my classroom neighbor ore someone who is sitting close to me. 


\section{Appendix B}

\section{Modified items of the Coping with Boredom Scale}

\section{Cognitive approach}

When I am bored in the classroom ...

1) ...I try to pay attention to the lesson more.

2) ...I tell myself to concentrate again.

3) ...I make myself aware of the importance of the issue.

4) ...I try to make myself aware that this class is important.

5) ...I make myself focus again because the issue is important.

\section{Behavioral approach}

When I am bored in the classroom ...

1)...I ask my instructor if we can do something else.

2) ...I ask my instructor for more interesting tasks.

3) ...I suggest that the instructor add variety to the lessons.

4) ...I try to get the instructor off topic so that we discuss an issue that interests me.

5) ...I bring up an issue that I think the class is more interested in.

\section{Cognitive avoidance}

When I am bored in the classroom ...

1)...I prepare for my next class.

2) ...I do my homework.

3) .... study for another subject.

4) ...I think about my homework or something I have to study.

5) ...I copy the homework for my next class.

\section{Behavioral avoidance}

When I am bored in the classroom ...

1) ...I talk to the person sitting next to me.

2) ...I start talking to my classmate sitting next to me.

3) ...I distract myself by interacting with my classmates.

4) ...I try to contact other classmates who are feeling also bored.

5) ...I occupy myself with my classroom neighbor ore someone who is sitting close to me. 


\section{Appendix C}

\section{Items of Multidimensional State Boredom Scale}

\section{Disengagement}

1) I am stuck in a situation that I feel is irrelevant.

2) Everything seems repetitive and routine to me.

3) I seem to be forced to do things that have no value to me.

4) I feel bored.

5) I am indecisive or unsure of what to do next.

6) I want to do something fun, but nothing appeals to me.

7) I wish I was doing something more exciting.

8) I am wasting time that would be better spent on something else.

9) I want something to happen but I'm not sure what.

10) I feel like I'm sitting around waiting for something to happen.

\section{High Arousal}

1) Everything seems to be irritating me right now.

2) I am more moody than usual.

3) I feel agitated.

4) I am impatient right now.

5) I am annoyed with the people around me.

\section{Low Arousal}

1) I am lonely.

2) I feel down.

3) I feel empty.

4) I feel cut off from the rest of the world.

5) It seems like there is no one around for me to talk to.

\section{Inattention}

1) I am easily distracted.

2) It is difficult to focus my attention.

3) My attention span is shorter than usual.

4) My mind is wandering.

\section{Time Perception}

1) Time is passing by slower than usual.

2) I wish time would go by faster.

3) Time is dragging on.

4) Time is moving very slowly.

5) Right now, it seems like time is passing slowly. 